\title{
Contestation and Co-optation: Why Secrecy in EU External Relations varies.
}

\begin{abstract}
The question posed in this article is how to explain that the governance of secrecy in EU external relations varies. While the Common Foreign and Security Policy appears to retain its secretive character, the EU's external trade policy has recently seen a shift towards more transparency. This article argues that to understand this variation, one has to take into account the institutional power of the European Parliament as well as the extent to which the rules and practices of secrecy are perceived as legitimate. The empowerment of the Parliament in trade means that it has had recent success in pushing back secrecy in this area. However, a general finding is that the majority of parliamentarians seem only rarely to question the executive's governance of secrecy in external relations. The analysis shows that perceptions of legitimacy are crucial to account for different secrecy regimes - a finding that is likely to be relevant for the understanding of secrecy in foreign policy beyond the EU.
\end{abstract}

\section{Introduction}

"More transparency" appears to have become the preferred solution to a range of problems in modern politics, and the key to achieve better governance (Hood and Heald 2006). As a result, '[g]overnment documents are being released, votes are published, and deliberations are being broadcasted on the Internet' (de fine Licht et al. 2014: 111). While public policy in general is opening up, the approach to transparency in external relations is a lot more cautious. This is an area that has long lived comfortably under a thick veil of secrecy (Frank and Weisband 1974, Roberts 2006), commonly relieved of the same democratic procedures as domestic policies (Sjursen 2011). ${ }^{1}$

The European Union (EU) has also felt the push for more openness and has responded by incorporating the transparency principle into its treaties. In the EU as well, external relations are largely exempt from the main rules regulating access to EU-documents. Still, recent developments suggest an emerging differentiation in the secrecy regimes of EU foreign affairs. Particularly in the area of trade, the 'paradigm of confidentiality' is described as waning (Hillebrandt 2017: 200). While the EU used to

\footnotetext{
${ }^{1}$ This article uses a wide definition of foreign policy meaning 'the sum of official external relations conducted by an independent actor (...) in international relations' (Hill 2003: 3). Thus, external relations and foreign policy are used interchangeably.
} 
conduct its trade negotiations safely behind closed doors, the talks with the US on the Transatlantic Trade and Investment Partnership (TTIP) forced a renovation of its traditional policy of secrecy. By contrast, overall access to Common Foreign and Security Policy (CFSP) documents is in decline and several member states are becoming more careful in exchanging information in this area (Hillebrandt 2017). Furthermore, all Members of the European Parliament (MEPs) got access to confidential documents on TTIP, and several of the EU's negotiating documents were even made public, whereas information on previous agreements and other types of foreign policy is highly restricted. The question then is how to explain that the governance of secrecy in EU external relations differs.

This article proposes that studying the EU can teach us something about the factors that might challenge secrecy regimes in external relations, as well as what allows them to prevail. Whereas the concept of and constraints on transparency has received substantial attention during the last few decades, we know less about the functions and governance of secrecy in foreign policy (e.g. Gill and Spirling 2015, Lagassé and Saidemann 2017). ${ }^{2}$ The nature of the EU's political order is unresolved, including the organizational and normative underpinnings of inter-institutional relations and the constitutive principles of good government (cf. Olsen 2010), making it a useful case to develop theoretical expectations about possible reasons for variation in the governance of secrecy.

The governance of secrecy can vary along different dimensions. Central is the scope of secrecy, which means that secrecy can extend to fewer or more substantive issues, e.g. policy areas (Goetz and Rittberger 2017). Secondly, within each policy area, who has access to information and in how far will usually vary, which refers to the intensity of secrecy (ibid.). This article argues that the latter entails choices where roles and principles come into play, which means that decision-making will be based on contextual and normative considerations, while the former is contingent particularly on the institutional powers of parliaments. ${ }^{3}$ By analysing a set of processes where efforts have been made to amend how secrecy is governed in EU

\footnotetext{
${ }^{2}$ A notable exception is the field of intelligence, encompassing issues of both internal and external security (e.g. Barrett 2005, Roberts 2006, Lester 2015).

3 This article focuses on the powers of the parliament, but the argument could potentially be extended to e.g. courts as well.
} 
external relations, the article demonstrates how the European Parliament (EP) has reduced the scope of secrecy by strategically using its institutional powers. It also shows that the majority of MEPs seem only rarely to question how the Council governs the intensity of secrecy in the field. When the legitimacy of secrecy has been publicly contested, as is the case for some trade negotiations, the EU executives have given way. A contrasting tendency, it is argued, is that parliamentarians become coopted by the culture of secrecy in foreign policy and therefore continue to let the executive set the premise for how secret information is governed, thus reinforcing the rule of secrecy in this area.

\section{Explaining Variation in the Governance of Secrecy}

This article seeks to account for the variation in secrecy governance between, and within, the CFSP and EU external trade policy. ${ }^{4}$ In doing so, it focuses on the activities of the EP, building on the claim that '[p]arliament has consistently argued in favour of openness and contrasted its behaviour in this regard with that of the Council' (Corbett et al. 2007: 331, see also Hillebrandt et al. 2014). This does not presume that the EP will prioritise public access to documents at all times, nor that it is alone in influencing secrecy policies at the EU-level. Nevertheless, being one of two legislators, the EP is in a prime position to make changes happen. The public is not only dependent on parliament for making information available, indirectly, it also depends on the ability and willingness of parliamentarians to challenge the secrecy rules of the executive.

Secrets can be defined as intentionally withheld information (Scheppele 1988). Building on Goetz and Rittberger (2017), this article distinguishes between two key dimensions of secrecy: scope and intensity. Secrecy in scope refers to the range of substantive issues with restrictions on openness. This can mean different policy areas, but also parts of policies or specific actors or agents. One way to think about the scope of secrecy is in terms of exceptions to general rules of access to information. These may extend to fewer or more issues, such as defence or diplomacy, but also more encompassing provisions such as "fundamental interests of the state". 5 Furthermore, most parliaments will have particular rules for access to information

\footnotetext{
${ }^{4}$ CFSP also encompasses the Common Security and Defence Policy (CSDP).

${ }^{5}$ Note that different rules can apply according to who is in possession of the information (e.g. Jørgensen 2014).
} 
withheld from the public (Colaresi 2014), so scope also pertains to parliamentary rights. Over the past decades, parliaments have for example become more active in overseeing intelligence agencies (e.g. Born and Caparini 2007).

Secondly, secrecy and transparency in external relations is usually debated along two axes of authorisation and accountability: between the executive and the public and between the executive and the parliament (Colaresi 2014). At stake then, is rather who shall have access to information and in how far, which refers to the intensity of secrecy. Parliamentary oversight committees in the field of intelligence and security for example, vary a lot in composition. A recent study by Wills et al. (2011) showed that such committees might consist of everything from 3 to 17 members. Some are composed only by parliamentarians, while others include a broader set of actors. Furthermore, how many - and who - have access to secret information differs according to level of classification. Only a few people will have access to top secret documents, for example, whereas restricted documents can be shared somewhat broader (ibid.).

To make sense of the observed differences in governance of secrecy in security and trade, two explanations are proposed: One relying on difference in institutional powers that explains the variation in scope, and one that explains variation in intensity as shaped by perceptions of legitimacy. Using a domain of application approach allows for a precise explication of how each explanation works, whilst taken together, they render a larger picture (Jupille et al. 2013: 21). In this case they give a more comprehensive understanding of EU's secrecy regime in external relations.

\section{Explaining Change in the Scope of Secrecy}

There are three main reasons why parliaments are normally less involved in foreign affairs than in domestic policies. First, parliaments are legislative institutions, but in foreign policy there is little legislation. Secondly, foreign affairs are rarely a major topic during election campaigns, which means that parliamentarians seeking reelection have little to gain from focusing on foreign policy. Thirdly, those who conduct foreign policy - governments and their agents - are closer to the sources of information than those who are supposed to scrutinise and control them. Thus, even parliaments who have extensive constitutional rights, 'face the problem of information asymmetry, and indeed much of parliamentary activity focuses on getting 
timely and accurate information' (Raunio and Wagner 2017: 9). In most other policy areas, parliaments are likely to get help from media and other third parties to keep check on the executive, but because so much of the information in external relations is secret, this option is thwarted (cf. Kibbe 2010). As a result, access to information from executive actors becomes even more important for parliamentarians.

We know that parliamentary powers in the field of foreign policy vary. Some parliaments have authority over deployment of troops, some over the defence budget but not on the decision to go to war, some parliaments are hardly involved in foreign policy-making, whether with regard to military matters or treaty-making (e.g. Raunio 2014, Peters and Wagner 2014). Formal powers and resources are important factors in accounting for differences in parliamentary involvement (e.g. Born and Hänggi 2005), and institutional powers are also likely to affect parliament's ability to influence rules on secrecy. The constitutional changes in France in 2008 intended to reform the legislative-executive relationship also strengthened parliaments rights to be informed by the executive about troop deployment (Ostermann 2017: 102). When parliament controls the purse, it can make funding conditional on being informed, including about so-called "black budgets", i.e. parts of the budget that are kept secret (cf. Rubin 2007). If they have sufficient institutional leverage, they might even reduce secrecy through legislation. The US Congress for instance established distinct rules through the Atomic Energy Act in order to protect nuclear-related "Restricted Data" (Elsea 2017: 2). Thus, it is reasonable to assume that institutional powers are linked to scope of secrecy in two ways. First, institutional powers are likely to correlate with scope of secrecy because parliaments that have more extensive roles in foreign policy will also have broader rights to information. Secondly, institutional powers can be used to shape existing or new secrecy regimes.

The history of the European Parliament can be described as a continuous fight for more influence over policy-making and the ability to control and scrutinise the executive. Because information and knowledge is such a treasured commodity in external relations, one would expect the EP to use its institutional powers to shape the governance of secrecy in order to be able to scrutinise the EU executives in as many policies as possible. In the field of security, the EP's powers are constrained, which limits what it is able to achieve. Although the EP has increased its informal influence 
over the CFSP, its formal powers have basically remained the same since Maastricht. According to Article 36 (TEU), the EP is supposed to be informed and consulted on the main choices and basic principles of the policy, can ask questions, and hold debates. ${ }^{6}$ For a long time, trade policy was subject to similar constraints. Under the Nice Treaty, Article 133 (TEC) did not provide for any involvement of the EP in the external trade policy (Rosén 2017). Against this background, the changes in the Lisbon Treaty represent a considerable transformation. After its entry into force, the EP has consent powers over 'virtually any international agreement (...) of any significance' (Corbett 2012: 249). ${ }^{7}$

During the Convention for the Future of Europe, which prepared what eventually became the Lisbon Treaty, the decision to extend the powers of the EP was largely motivated by legitimacy concerns (Rosén 2017). Between treaty reforms, however, the increase of parliamentary influence is predominantly depicted as a result of the EP's bargaining strategy, where the outcome hinges on relative powers and formal decision-making rules (Hix 2002, Farrell and Héritier 2003). In the words of Rittberger (2012: 20): 'once actors have agreed on the basic institutional structure, strategic distributive bargaining is likely to ensue over the distribution of decisionmaking powers'. Formal powers give the EP the opportunity to obstruct and delay political processes - or threaten to do so - thereby putting pressure on the Council and the Commission to concede to its demands (Farrell and Héritier 2007). If the Council is more eager to achieve a quick deal, this would increase the credibility of a threat by the EP to obstruct policy-making. Similarly, 'justiciability of the matter' can increase an actor's bargaining power (ibid: 233-234). Although the role of the Court is restricted in the area of the CFSP, appealing to the Court could still have an effect if the Court decides it has jurisdiction, or if the Council wishes to avoid an unwanted precedent. Therefore one could expect that the greater the formal powers of the EP, the more successful it will be in pushing back secrecy, offering a plausible account for the differences between the areas of security and trade.

\footnotetext{
${ }^{6}$ In addition, it has used indirect powers to enlarge its involvement. Especially the power of the CFSPbudget has been an efficient lever for the EP to establish rules and procedures for information and control (Rosén 2015).

7 The EP's consent powers do not encompass international agreements in the field of CFSP (Article 218(6), TFEU).
} 
While such an explanation is likely to have merit, it is unlikely that the EP would demand eradication of all forms of secrecy, even if it had the power to do so. To scrutinise the executive the EP needs access to information, and is likely to use its bargaining powers to reduce secrecy across policy areas. However, most countries in the world have specific rules aimed at safeguarding sensitive information that could harm national security or national interests if disclosed, and many regard this as legitimate (Colaresi 2014). In other words, the scope of secrecy can be explained by interinstitutional bargaining, but the question about who should have access to what type of information is more likely to be determined by considerations of appropriateness and legitimacy.

\section{Explaining Change in the Intensity of Secrecy}

Apart from the area of intelligence, the literature on secrecy in foreign policy is rather sparse, particularly on the intensity of secrecy. Only recently has the politics of international trade made a comeback on the agenda, sparking an interest in what takes place behind closed doors. Beyond the debate about if and how openness hinders efficient trade negotiations (e.g. Stasavage 2004, Kucic and Pelc 2015), we know little about to what extent parliaments or the public have access to documents. Until recently, the role of parliaments in foreign and security policy has also received little attention (Raunio and Wagner 2017: 1), and even less is written on how parliamentary access to documents varies in this realm (Lagassé and Saidemann 2017: 121).

Research on the role of national parliaments in the EU, however, suggests that access to information varies across the member states, and that some parliaments have access to classified documents, while others only to lower levels of classification or not at all (e.g. Maurer 2015, Jancic 2017). ${ }^{8}$ As in the area of intelligence, the parliamentary procedures for accessing secret information in the realm of security also differ across the EU. ${ }^{9}$ The reasons for this variation are largely unaccounted for. ${ }^{10}$

Arguments about the need for secrecy in external relations pertain especially to the intensity of secrecy. Secrecy is seen as more legitimate in foreign policy than in other policy areas. Not only does the public tolerate secrecy when the costs of transparency are detrimental to foreign policy goals (Colaresi 2014), parliaments too tend to be less

\footnotetext{
${ }^{8}$ See also COSAC, 23rd Bi-annual Report, http://www.cosac.eu/documents/bi-annual-reports-of-cosac. ${ }^{9}$ PE 296.415/Bur

${ }^{10}$ But see Lagassé and Saidemann (2017) who focus on party-political factors.
} 
conflict-seeking (Raunio and Wagner 2017). In the words of Roberts (2006: 42): the 'assumption that the defense of national security demands strict controls on the flow of information is deeply embedded in bureaucratic - and popular - culture'. There are two main aspects to the legitimacy of secrecy: it may be seen as legitimate to keep some forms of information secret, either because of the costs involved if they are revealed or because certain actors are perceived as the appropriate authorities to keep some types of information secret (Pozen 2010). Firstly, democracy demands transparency, but some democratic policies may also require secrecy, and the tricky part is to balance these two needs (Thompson 1999: 182). When discussing the intensity of secrecy, then, legitimacy concerns arise because who gets access to what type of information determines the extent to which the public and parliaments are able to scrutinise the executive. On the flipside, too much openness may jeopardize other, legitimate, interests. When discussing the intensity of secrecy in external relations, differentiation between actors who have access to all, some or no secret information is to be expected also concerning non-security issues because some degree of secrecy is considered justifiable.

Secondly, secrecy may also be seen as legitimate because the executive is held to be the appropriate actor to manage confidential information. The making of foreign policy is something that is largely left to the government and its agents. Historically, foreign policy was considered a royal prerogative, and while the role of royalty has diminished, foreign policy is still seen as a matter for the executive (Bieber 2002). The institutionalisation of these different roles is likely to affect the perception of the appropriate rules and practices for handling secret information. Beyond the legitimacy of secrecy in itself, building on sociological institutionalism, some rules are seen as 'self-enforcing because actors have internalized the belief that some actions are appropriate, natural and legitimate' (Olsen 2009: 10). Huysmans (2014: 151) has for example emphasised how the management of security policy is characterised by 'technocratic politics in which authority is vested in knowledge and technical skills'. Thus, when discussing the intensity of secrecy, without disregarding that secrecy is also an instrument of power, acknowledging the cultural embeddedness of secrecy becomes relevant. Not only are executive actors likely to see themselves as the appropriate managers of secret information, but parliamentarians might also ascribe to this division of labour. Curtin (2014: 8) has for example argued that a 'culture of 
secrecy' underpins the 'web of rules and arrangements' that governs secrecy in the EU. Thus, one would expect the intensity of secrecy to be associated with the pervasiveness of a secrecy culture. Moreover, it is reasonable to assume that such a culture is more prevalent in foreign and security policy where exceptionalist secrecy measures can be linked to the survival of the polity (cf. Bourbeau 2014). ${ }^{11}$

At the same time, actors are also capable of "criticising the norms that they are socialised under, and [of] choos[ing] different modes of action from what they are expected to and used to' (Eriksen 1999: 226). When there is disagreement over how to understand, or how to apply a set of rules and practices, there is less certainty about which rules and practices to follow and why. For secrecy to retain its legitimacy when it becomes contested, it will have to be justified with reference to reasons that are recognised as valid (cf. Eriksen 1999). In the field of trade for example, the new generation of EU trade agreements attempt to dismantle non-tariff barriers raising issues that are closer to home for voters, and hence have a larger mobilising potential. As a result, one could expect that there is a greater likelihood that the intensity of secrecy is challenged in the area of trade because more people will question the legitimacy of secrecy.

\section{How and Why Does Secrecy Vary in EU External Relations?}

This article analyses a set of processes where efforts have been made to amend the governance of secrecy in EU external relations. ${ }^{12}$ By comparing the CFSP and trade policy, the goal is to account for possible reasons why secrecy varies. The analysis looks at strategies and arguments used to promote transparency and defend secrecy as well as the extent to which these efforts have been successful. Furthermore, the chief focus will be on the EP, based on its track record as a champion for transparency as well as its institutional position. Although the EP's reputation on openness might not be flawless, as a legislator it is well placed to influence existing rules.

As indicated in the introduction, the governance of secrecy in EU external relations varies both with regard to scope and intensity. During the debate about the EU's

\footnotetext{
${ }^{11}$ It is important to note that this effect is likely to be even stronger in a national context.

12 The analysis is based on data consisting of official documents from the different EU-institutions as well as 30 interviews conducted in the period from 2010-2017, with MEPs, EP-officials, members of the Commission, Council secretariat, the European External Action Service, and representatives of the member states.
} 
Regulation on public access to documents (1049/2001) around the turn of the millennium, there was a massive debate about the exceptions to the general rule of access. According to the EU Ombudsman, the Commission's initial proposal for a list of exceptions was 'without precedent in the modern world' (cited in Heliskoski and Leino 2006: 744). Both the number and scope of the exceptions were reduced during the negotiations that followed, and more detailed conditions specified in subsequent case-law (ibid.). In the wake of the new regulation, in 2002, the EP secured an Interinstitutional Agreement (IIA) with the Council on access to sensitive documents in the area of security and defence. ${ }^{13}$ Only more recently, however, did it gain similar rights of access to other parts of the CFSP. There is also an emerging difference between the CFSP and trade policy. In the midst of the battle over TTIP, both the Commission and the Council revised their transparency policy. Conversely, recent studies show that access to CFSP-documents has decreased (Hillebrandt 2017). ${ }^{14}$

Furthermore, there is variation between and within policy areas in the intensity of secrecy. Under the 2002-IIA on access to sensitive documents in the area of security and defence, a select committee of five MEPs are allowed to read documents, but cannot share any of this information. For other CFSP-issues, the High Representative for foreign affairs and security policy (HR) has signalled that she is open to access to documents being given on a need-to-know-basis. ${ }^{15}$ In the area of trade, access was initially limited to 'the responsible Committee Chair, the coordinators of the political groups and the relevant rapporteur' (Devuyst 2014: 179). This changed in the context of the TTIP, when first a larger group of INTA members, and later all MEPs gained access to classified information. This also includes restricted documents, which inter alia comprise information on the US' negotiation positions. ${ }^{16}$

How then to make sense of these differences? This article puts forward two separate explanations: 1) that variation in scope is mainly a result of difference in institutional powers, and 2) that variation in intensity is affected by perceptions of legitimacy.

\footnotetext{
13 OJ 2002/C298/01.

14 Several policy areas fall under EU external relations, and this is likely to represent only some of the actual variation.

${ }^{15}$ OJ 2010/C210/01.

16 Letter to Cecilia Malmström from Martin Schulz and Bernd Lange, 2015:

http://www.europarl.europa.eu/cmsdata/110464/access-to-ttip-related-docs.pdf
} 


\section{Institutional Power and the Scope of Secrecy}

Concerning the scope of secrecy, one would expect that as the EP gains more institutional powers, it would use this as a lever to gain access to more substantive issues, reducing the executives ability to determine the rules and practices of secrecy unilaterally. If level of institutional powers affects the scope of secrecy, one would expect to see the EP trying - or threatening to - block and/or delay decision-making processes, or appeal to the Court, to force concessions from the EU executives. If successful, the latter's response would be to comply accordingly.

In 2002, after two years of negotiations, the EP and the Council concluded an Interinstitutional Agreement (IIA) on access by the EP to sensitive Council documents in the area of security and defence. The EP used two bargaining strategies to secure a deal with the Council: the threat of court proceedings and making its approval of the Regulation on public access to EU-documents (1049/2001) conditional on an IIA on parliamentary access to sensitive documents (Rosén 2015). The EP originally argued that a complete exclusion of a group of documents infringed the rights of citizens to obtain information ${ }^{17}$, and did contribute to reducing the initial list of exceptions (Heliskoski and Leino 2006), but issues pertaining to public security, defence, international relations and commercial interests remained (EP\#1, EP\#5). In the words of one MEP: '[t]hey had to give the secrecy advocates something in order to save the general principles' (quoted in Tallberg 2006: 154).

Regulation 1049/2001 has been heavily criticised. Some interviewees claimed it went very far in making blanket exemptions for whole groups of documents, without considering them individually (EP\#4, EP\#5). However, the lack of bargaining powers on the part of the EP limited its ability to shape the governance of secrecy. During the parallel negotiations, the Swedish presidency used the EP's demands to push reluctant member states to accept more transparency (NAT\#1, NAT\#2). At the same time, the Swedish presidency informed the EP that several issues were non-negotiable (NAT\#1). Most MEPs were eager to close a deal on the Regulation on public access as well as an IIA during the Swedish Presidency, because they doubted its successors' commitment to transparency (Conference of Presidents, 13/06/2001). In bargaining terms, this put the EP on the defensive. Not only was it more important for the EP to

17 PE 293.538. 
secure an agreement within the six months of the Swedish Presidency, if the Council postponed negotiations it would have no access to sensitive documents.

A set of contextual factors also played into the hands of the Council. In the summer of 2000, with High Representative Javier Solana at the helm, EU and NATO were preparing a deal on exchange of documents, aiming to formalise their relationship. A crucial NATO demand was that any intelligence sent to the EU would be properly protected (Reichard 2006). According to UK Europe Minister, Keith Vaz, the old exceptions were not held to be secure enough to protect documents concerning 'operational issues or highly classified material' in the wake of the newly established Common Security and Defence Policy (CSDP) (House of Lords 2001). ${ }^{18}$ Solana took the initiative to adjust to the "NATO-model", excluding top secret, secret and confidential documents from the 1993 Council Decision on public access to documents. Because this was done just before the launch of the negotiations on the new access to documents regulation, the issue of sensitive documents became one of the most difficult issues to resolve pitting the EP and member states who favoured an open approach against 'states with a strong security interest' (Bjurulf and Elgström 2004: 253).

Although the EP took the Council to court over the "Solana-decision", it was unable to change the gist of the decision. Not only did it not have sufficient bargaining leverage, the message from the executive was that the project of trying to establish the CSDP was fragile and could fail if the EP pushed to far on access to sensitive documents. In a bid to justify the introduction of the new rules to the EP, Solana explained: in an area 'so new and complex, the Member States had to be afforded certain guarantees, failing which they would refuse to take part in the establishment of a genuine security and defence Europe' (Conference of Presidents, 05/10/2000). While some MEPs expressed concern that the Council were allowed to set the premise for the governance of secrecy, the pragmatist majority appeared to accept the executive's argumentation. The rapporteur for the IIA, MEP Brok, argued: 'We are entering into new territory here and that is why learning is also the order of the day. We must not, however, go too far at the outset, because this is a very sensitive area

${ }^{18}$ Termed the European Security and Defence Policy at the time. 
and at stake are the security interests of the Member States of the European Union and all of our fellow citizens' (EP-plenary, 22/10/02).

There has been quite some disagreement between MEPs about the effect of the IIA especially because of the small number of MEPs who actually got access. At the same time, it did allow the EP to receive secret information on security and defence issues. No similar arrangement was established in foreign policy - the other leg of the CFSP - and access to documents here was given through ad hoc decisions (EEAS\#1, EP\#4, EP\#12). After the entry into force of the Lisbon Treaty, however, when the HR was working on the establishment of the European External Action Service (EEAS), the EP seized the opportunity to reintroduce the issue of access to sensitive documents. Two regulations that accompanied the establishment of the EEAS were subject to codecision, and these could not be passed without the EP's approval, giving the EP bargaining leverage (Raube 2012). Negotiations resulted in a move towards extending access to include CFSP documents (EP\#6). ${ }^{19}$ Recently, the EP has also taken the Council to Court, demanding the annulment of two international agreements with Mauritius and Tanzania on the transfer of captured pirates. One of the EP's main arguments was that it could not scrutinise the Council's activities because it did not have access to draft texts. ${ }^{20}$ In both cases, the Court ruled for the EP, arguing that the Parliament's right to information had been breached. The internal variation within CFSP again demonstrates how differences in institutional powers matter to the scope of secrecy. With more leverage to back up its demands, the EP has been able to successfully challenge the Council's governance of secrecy, also on CFSP-issues.

EU trade policy used to be governed similarly to the CFSP. Although external trade has been subject to Qualified Majority Voting since its inception, repeated calls for more powers by the EP were not successful. With the Lisbon Treaty, the EP all of a sudden gained both codecision powers over trade legislation and veto powers over trade agreements. Article 218(10) states that the EP is to be 'immediately and fully informed at all stages of the procedure for the negotiation of international agreements'. And under Article 207(3), the Commission is 'under a legal obligation to inform Parliament of the progress of negotiations on par with the special (...)

\footnotetext{
${ }^{19}$ See "Declaration by the High Representative on Political Accountability", OJ 2010/C210/01.

20 C-658/11 and C-263/14.
} 
committee of the Council'. Several interviewees underlined that the Council has had considerable difficulties coming to terms with the EP's new role, and that particularly the latter paragraphs caused conflict because it meant sharing confidential information.

One day before the entry into force of the Lisbon Treaty, the Council signed the SWIFT-agreement on exchange of banking information with the US. In its resolution a few months prior, the EP had made clear that its new consent powers should be acknowledged and that it expected to gain access to all negotiations documents. ${ }^{21}$ When the Council did not listen, the EP refused ratification demonstrating that it was now able to put weight behind its demands. Shortly before the EP vetoed the agreement, the Council approached the Parliament with a letter, expressing the wish to negotiate an IIA on access to classified information regarding international agreements. The response from the EP-president was stern: despite repeated warnings from the EP, its concerns were not 'given the attention they deserved'. In addition, he underlined: 'if the Parliament is to have a right of veto over agreements which contain "classified" components (...) then it follows logically that the Parliament needs to be in a position to make a considered and serious judgement about the content and significance of such elements'. ${ }^{22}$

Although not a trade agreement, SWIFT was a token of what was to come in the field of trade as well. During the negotiations of the Anti-Counterfeiting Trade Agreement (ACTA), the EP's access to information triggered a new conflict. At one point, the EP underlined that unless it were 'fully informed at all stages of the negotiations' it would reserve its 'right to take suitable action, including bringing a case before the Court of Justice in order to safeguard its prerogatives'. ${ }^{23}$ The EP's threats prompted a quick response from the Commission. In November 2010, the two concluded a Framework Agreement, where they settled on how to interpret Article 207(3). In practice, the agreement entails that the EP receives all the information that the Commission gives to the Council (COM\#5). The negotiations between the EP and the Council on a new IIA on access to classified information took considerably longer. The final round of negotiations dealt with the scope of the IIA, which initially also

\footnotetext{
${ }^{21}$ P7_TA(2009)0016.

${ }^{22} \mathrm{PE}$ 443.243/CPG.

${ }^{23}$ P7_TA(2010)0058
} 
included CFSP-documents (Bornemann et al. 2016). None of the member states supported this, however, and France threatened to veto the entire IIA if CFSPdocuments remained in, so the necessary changes were made (ibid.: 16). Again this illustrates the EP's lack of leverage over the CFSP. In the autumn of 2012 an agreement was finally reached, covering classified information held by the Council, except for the area of CFSP. ${ }^{24}$ Differences in institutional powers consequently give a plausible account of why the EP has been able to make a greater advance vis-à-vis secrecy in the case of trade. According to one interviewee, if the EP is deprived of access to information on trade, it will frustrate the relationship between the Council and the Parliament (COU\#2). In the words of an interviewee from the EP, '[n]ow that we have codecision and consent for international agreements, we have all the tools to control the Commission and also to see how the member states envisage action. But this fails in the CFSP-area' (EP\#2).

In addition to being part of an unsettled polity, there is no government emanating from the EP, which makes it similar to the American system of checks and balances (Hix and Høyland 2014). The EP is known for its continuous quest to empower itself, and most national parliaments do not have that kind of relation to their executives, nor do they have the same need to justify their own existence (Bieber 2002). Thus, the conditions under which the EP will use its institutional powers to reduce the scope of secrecy are probably somewhat different from its national counterparts. In parliamentary systems, political parties constitute important channels of information, which means that parties in opposition might be more inclined to advocate reducing the scope of secrecy than parties in government (cf. Lagassé and Saidemann 2017). At the same time, because foreign policy is only rarely subject to party political competition, one could expect such efforts to coincide with external events and/or potential reputational costs. The setting up of parliamentary oversight committees in the field of intelligence following scandals is one example of how such efforts might be triggered (e.g. Born and Caparani 2007). It is important to note that the executives themselves also have an interest in reducing the scope of secrecy in moments of such crises. In EU trade policy, research shows that the Commission has urged for greater transparency to refute accusations of illegitimacy (Coremans 2017). What this study

\footnotetext{
${ }^{24}$ OJ 2014/C095/01.
} 
of the EP demonstrates, however, is that the scope of secrecy follows closely its institutional role. This should also hold for national parliaments: their right of information is likely connected with their institutional and constitutional powers, even if they might not be as willing - or have the same need - as the EP to use those powers for bargaining purposes.

Still, having a right to information does not establish the details of access. Thus, this article argues that an aspect of the variation in secrecy that differences in institutional powers do not account for are the rules and practices regulating who has access to information and in how far. Despite the latest advances in the area of CFSP for example, interviewees depict the field of foreign and security policy has highly secretive. They describe how there is no list of documents that MEPs can consult so as to know what to ask for, that they therefore depend on the Council being proactive, and that there is considerable unwillingness to establish arrangements that could ease the exchange of secret information (EP\#11, EP\#12, EP\#13). Moreover, striking the balance between public and parliamentary access to documents is a continuing discussion in the EP. In the first plenary debate on the Regulation 1049/2001, the majority of speakers denounced a blanket exemption of sensitive documents. The EP's first draft report of the Regulation also argued that the general rule should be public access, that exceptions should not be mandatory and determined on a case-bycase basis (Heliskoski and Leino 2006: 744). However, during the negotiations, the EP itself was split on how far it should take its demands (EP\#1, EP\#4). According to one interviewee, the reason the 2002-IIA did not go further was that 'the proopenness MEPs did not manage to convince the rest of the EP' (EP\#5). Similar observations are made in the area of trade. Some MEPs have gone to great lengths to promote public transparency, taking the Council's refusal to disclose documents to the Court even (e.g. Abazi and Hillebrandt 2015). For some trade agreements, the EP has argued against public disclosure on the grounds that confidentiality protects EU interests during negotiations, although for others it has made vigorous demands for public access to documents. Thus, on the issue of intensity of secrecy, there is again variation both between, as well as within, policy areas. To understand these differences one has to take into account how perceptions of legitimacy affect beliefs on who should have access to what types of information. 


\section{Legitimacy and the Intensity of Secrecy}

The intensity of secrecy is likely to be shaped both by principled considerations about the right balance between openness and secrecy as well as culturally embedded roles and identities. If perceptions of legitimacy explain variation in the intensity of secrecy, one would see actors referring to the legitimacy of rules and practices when defending secrecy measures. When technocratic routines are not questioned, this can also be interpreted as a tacit acceptance of the appropriateness of secrecy (cf. Rittberger 2012). By contrast, if contestation of claims to legitimacy has an effect on secrecy rules, one would expect to see change justified with reference to arguments denouncing the legitimacy of existing secrecy rules (cf. Rosén 2016).

After the Interinstitutional Agreement (IIA) on access to sensitive documents in security and defence was concluded in November 2002, many MEPs claimed that the agreement would actually limit the Parliament's access to documents. The Council could withhold documents from the EP, security was defined too broadly in the IIA, too extensive veto powers had been given to third parties because of originator control $^{25}$ and the arrangement in the IIA gave too little information to too few (Tappert 2003). Especially MEPs from the Greens were outspoken about what they saw as a tendency for the Parliament to prioritise parliamentary over public access. During the early stages of the negotiations, MEP Hautala warned: 'the right of the Members of Parliament to confidential documents is a very important issue, but it cannot replace the direct access to information on the part of the public' (EP-plenary, 16/11/00). Her party colleague MEP Lagendjik put it even more strongly: 'as I see it, a link has been established - erroneously so - between the rights of parliamentarians and the rights of the public' (ibid.). Although the whole of the Parliament did not agree that the chosen secrecy regime was legitimate, the arguments for greater openness did not resonate with the majority of MEPs, and thus had little impact on practice. Furthermore, those who criticised the level of secrecy in foreign policy were careful to underline that their pleas for openness did not contradict the necessity of protecting certain types of information (EP-plenary, 22/10/02).

\footnotetext{
25 The principle of originator control (orcon) 'provides that information may not be downgraded, released or declassified without the consent of the originating government or executive entity' (Curtin 2014: 8). The orcon-principle encompasses both third parties and member states.
} 
In a letter to the EP-president, a couple of weeks after the "Solana-decision", the two chairs of the Committees on Legal Affairs and Foreign Affairs, MEPs Watson and Brok, stated that 'subject to appropriate conditions and procedures, we must ensure the confidentiality of documents which if they are leaked might endanger the internal and external security of the Union or its Member States'. Then they added: '[u]nder exceptional circumstances, democratic controls might even have to be carried out by a select committee of the European Parliament'. ${ }^{26}$ These statements echo the rhetoric of Solana and of the member states concerned about secrecy. Openness is seen as an indirect threat to security. It is not surprising that parliamentarians admit to a need for secrecy, but the EP never got back to defining the exceptional circumstances that would trigger use of the special committee.

The EP also went further in adjusting to the Council's position. Hillebrandt (2017) has described how the creation of the CFSP initiated a new security culture around the Foreign Affairs Council. Particularly the office of the HR and bodies such as the Political Security Committee consisted of personnel used to working under a cloak of secrecy. Before the 2002-IIA could be implemented, the EP had to alter its Rules of Procedure to incorporate a set of security regulations similar to those of the Council (Conference of Presidents, 13/03/02). This was an absolute demand from the EU's largest military powers. Having similar security regulations across the institutions alleviated the worry that the EP would not follow proper procedures for handling sensitive documents, and hence leak them more easily (Rosén 2015). Prior to the vote on these security rules, MEP Hautala criticised the lack of an open debate about the new procedures, arguing that some of the measures were 'very problematic' (EPplenary, 23/10/02). The way the content of the rules was never a subject for broader discussion illustrates how Parliament adapted to the technocratic security practices without questioning (cf. Curtin 2014). Thus, the majority of MEPs accepted that the Council set the premises for parliamentary security routines as well, adopting the allusions to the risks involved if these matters should be discussed openly. This form of tacit tolerance is another indication of how the majority of MEPs hold the Council's secrecy regime to be appropriate.

26 PE 293.545/BUR. 
The EP has tried to extend the terms of the arrangement, arguing that access to information should be based on the need-to-know principle. Some advances have been made, where for example the rapporteur has been allowed into the select committee meeting even if (s)he is not a formal member (EP\#6). Another development is that staff are normally allowed into select committee briefings, although they are not permitted to see copies of documents (EP\#11). While the EP's pragmatic reasoning has been met with a certain degree of understanding from the $\mathrm{HR}(\mathrm{s})$ (EEAS\#1, EP\#6, EP\#11, EP\#12), the EEAS is subject to the least-common denominator logic, where the more secretive member states often get to decide which documents to keep secret (EEAS\#3). The Council, is described as the most restrictive of the EU-institutions by all interviewees, and as very careful to adhere to the proper procedures for dealing with secret information. Interviewees describe situations where - during briefings - MEPs have been told that certain information, e.g. strategic documents, can only be provided to the five members of the special committee (EP\#6).

Interviewees also describe the special committee-solution as very restrictive (EP\#3, EP\#6), and that the procedures in place make access to classified documents cumbersome (EP\#11, EP\#12). Members of the special committee need security clearance from their own member states, which can take a very long time. ${ }^{27}$ Moreover, MEPs have to know about the documents they want to access in advance, because the list of classified documents itself is secret (EP\#11, EP\#12). Still, several MEPs appear to prefer the arrangement (EP\#6, EEAS\#1), and do not want a new agreement (EP\#11). One reason might be that the special committee is not used primarily to access documents. Instead, it has become regular practice that the HR briefs the committee orally, often in connection with the plenary sessions in Strasbourg (EP\#6, EP\#11). This was commenced under Solana, and continued by both Ashton and Mogherini. The arrangement has been described as 'very interactive', where the MEPs can discuss on-going policies with the HR (EP\#6, EP\#11). These briefings of the special committee illustrate how rules of secrecy become institutionalised, enabling security officials to continue to remove issues from

\footnotetext{
${ }^{27}$ In the case of the ad hoc procedures followed for CFSP-documents, it can cause considerable problems for MEPs who are rapporteurs, because it might take up to half a year to get clearance (EU Observer 2010).
} 
the sphere of normal politics through the establishment of specific procedures, and without prior debate. Some interviewees underlined how the development of trust is important to the continuation of the practice (EP\#1, EP\#12, NAT\#1). Thus, MEPs are faced with a dilemma likely to haunt other parliamentarians as well. If they accept strict secrecy rules, they also get access to more information.

Together with 'public security' and 'defence and military matters', 'financial, monetary or economic policy of the Community or a Member State' are also on the list of exceptions to the general rules of public access to EU documents (Article 4, Regulation 1049/2001). Although trade policy may not be essential to the survival of a polity, secret negotiations are commonly considered a prerequisite to be able to promote and protect public interests. Disclosing information either on negotiating positions or room for manoeuvre may risk undermining those interests. As described above, the negotiations between the Council and the EP on access to classified documents began immediately after the Lisbon Treaty entered into force, but progress was slow. Half a year after talks had begun, several EP committees, including INTA, reported that they were experiencing practical difficulties in accessing information from the Council. Access was given only under very restrictive terms, i.e. access on Council premises and only for a limited number of MEPs (Conference of Presidents, 30/06/11). The EP and the Council had quite different interpretations of how the new treaty provisions were to be implemented, particularly with regard to who should access to documents, where documents could be accessed, and what MEPs should be allowed to see (COU\#3, EP\#6, EP\#7, EP\#12, EP\#13, NAT\#5, NAT\#6).

One of the Council's key demands was that MEPs should have security clearance to access confidential documents. This overlaps with the demands that the MEPs are confronted with for sensitive documents in the field of CFSP and CSDP. The attempts at imposing a similar security practice were less successful in the case of trade, however. The new IIA established an arrangement where documents are made available to MEPs on a need-to-know basis, limited to members of the relevant committee as well as other specialised EP bodies. Compared to the rules in the IIA in the area of security and defence, the new arrangement is more open where more MEPs gain access to information, instead of only a preselected group. Furthermore, EP staff can access documents as well, and security clearance is not required for 
documents up to the level of EU Confidential. Findings indicate that very restrictive secrecy rules are regarded as less legitimate for trade. Some interviewees for example underlined that the solution of a select committee can be justified for security and defence, but not for other fields (EP\#2).

Still, before the new IIA could be implemented, the EP had to adapt its security regulations again. The main problem - according to the Council - was the lack of secure facilities in the Parliament. In June 2011, the EP adopted new security rules that were supposed to govern the "creation, reception, forwarding and storage of confidential information by the European Parliament'. ${ }^{28}$ In the meantime, however, the Council had adopted another set of security regulations, which meant that the EP had to change its rules yet again. Then before the IIA could be implemented, and the EP could access documents on its own premises, equivalence had to be established between the standards and levels of protection of the EP and the Council. For restricted documents, this was done in April 2014, but it took another two years - and a 'follow-up technical visit' by the Council Secretariat's Security Office, until equivalence was declared for confidential and secret documents as well. ${ }^{29}$ According to some interviewees, another reason it took so long to finalise the IIA was internal debates in the EP about whether the Parliament should establish its own arrangements for secret information (EP\#11), but those opposed did not win through.

The EP's adjustments to the Council's rules illustrate how secrecy routines spill over into other areas, by way of rule management. Security experts are allowed to set the premises for the handling of sensitive documents in several areas of external relations. ${ }^{30}$ This is also evident in the cases where the EP needs access to documents from the EEAS (EP\#12). One interviewee, for example, talked of the tension between political leaders who might be willing to be more lenient towards the EP, while security staff are much more careful (EEAS\#1). Another emphasised the differences in national cultures that the EEAS has to adjudicate, and where the member states with the strictest secrecy cultures are often allowed to set the standard (EEAS\#3). However, in implementing its new security rules, the EP is also described as 'more holy than the

\footnotetext{
${ }^{28}$ OJ 2011/C190/02.

${ }^{29} \mathrm{http}: / /$ data.consilium.europa.eu/doc/document/ST-8870-2016-INIT/en/pdf.

${ }^{30}$ There are also interesting differences between Commission's DGs, where those DGs that deal with matters of security are more secretive (EP\#12), which indicates that secrecy governance not only depends on institutional divides but also of substance.
} 
pope' (EP\#12). In order to avoid leaks, it has changed its Rules of Procedure to reinforce the sanctions against MEPs who breach the security rules. If confidentiality is compromised, limitations can be placed on an MEP's access to confidential or classified information for up to one year, and this may be doubled in case of repeated offenses (Rule 166). This indicates that the EP - whilst it conceives of its own role in a very different manner in trade compared to security - is nevertheless eager to comply with the Council's efforts to retain secrecy in the area of trade as well. Thus, with regard to the intensity of secrecy, there are some significant similarities between security and trade. Although the legitimacy of secrecy in itself may be less predominant in trade compared to security, the appropriateness of the secrecy rules and practices created by security officials are rarely contested.

In this sense, the negotiations on the trade agreement between the EU and the US changed the rules of the game quite considerably. TTIP became subject to unprecedented public interest and a lot more contentious than anyone expected. After heavy criticism of the way in which the EU conducted its negotiations with the US, the Commission launched a new transparency strategy, a little more than a year into the talks, 'in order to win public trust and support for the TTIP'.${ }^{31}$ Not only did all MEPs eventually get access to all confidential TTIP documents ${ }^{32}$, but the Commission's communication also increased massively, with publication of fact sheets and summaries of the results of each negotiating round. It also published the negotiation mandate - although some member states were highly sceptical (NAT\#6). All interviewees that have dealt with TTIP contended that the secrecy surrounding the negotiations became a legitimacy problem. Several underlined how the TTIP-debate created a need to respond to the engagement from civil society, and to demonstrate to citizens that the Council and the Commission are not trying to keep anything hidden (COM\#5, NAT\#6). Faced with massive normative pressure - questioning the legitimacy of secrecy - from national parliaments, civil society, the EU ombudsman, and including several member states, the situation became untenable and lead to reforms adjusting the intensity of secrecy surrounding (at least some parts of) the negotiations.

\footnotetext{
${ }^{31}$ Press release: http://europa.eu/rapid/press-release_IP-14-2131_en.htm.

${ }^{32}$ Press release: http://www.europarl.europa.eu/news/en/news-room/20151202IPR05759/all-meps-tohave-access-to-all-confidential-ttip-documents.
} 
TTIP is expected to set a precedent for how the Commission handles sensitive information in future negotiations, still most interviewees are clear that TTIP was an exception. Although the Council has decided to publish the negotiating mandate for the Trade in Services Agreement (TiSA) as well (which is also a controversial agreement in several countries), the TTIP-debacle seems to have brought about few permanent changes to the governance of secrecy - thus far. The question is whether and to what extent changes to the intensity of secrecy caused by legitimacy challenges produces lasting effects. This is not least because the EP is less than consistent in how it approaches public access to information in external relations. In the EP's resolution on the opening of the TTIP negotiations from 2013, there is a section on the role of the EP, cautioning the Commission to remember its obligation to inform the Parliament about the negotiations. The only reference to citizens is when the EP 'reiterates its basic responsibility to represent the citizens of the EU' ${ }^{33}$ This is echoed in plenary debates where some MEPs argued against public access on the grounds that citizens have little to gain from reading the negotiation mandate, and that it is the job of the representatives to act on their behalf (MEP Caspary, EP-plenary, 22/05/2013).

Two years later, the EP's resolution contained a section with seven paragraphs on 'transparency, civil society involvement, public and political outreach', the first of which underlines the need to make 'more negotiating proposals available to the general public'. ${ }^{34}$ In the case of SWIFT, a handful of MEPs argued for public access to documents, but the EP's resolution did not mention public transparency. With ACTA, the call for public access was made more forcefully: The EP called on the Commission and Council to 'grant public and parliamentary access to ACTA negotiation texts and summaries' ${ }^{35}$ However, in response to an investigation by the EU Ombudsman of the EP's refusal to disclose ACTA-documents, Parliament argued: 'international agreements are based on a process, the confidentiality of which must be protected even after the negotiations have ended. There is a concrete risk that disclosure of preparatory documents would prejudice not only relations with third countries in the context of ACTA, but also any other negotiation to be conducted by the EU in the future'. ${ }^{36}$ The EP's wavering position indicates that perceptions of

\footnotetext{
${ }^{33}$ P7_TA(2013)0227.

${ }^{34}$ P8_TA(2015)0252.

35 P7_TA(2010)0058.

$36 \mathrm{http} / / / \mathrm{www}$. ombudsman.europa.eu/en/cases/decision.faces/en/50947/html.bookmark.
} 
legitimacy are key to understand differences in the governance of secrecy, and equally important why secrecy in EU external relations does not vary more.

In the case of security and defence there was not enough support in the EP to push for less secrecy. It was also a debate that did not get much outside attention. By contrast, the case of TTIP illustrates how the intensity of secrecy is vulnerable to contestation on grounds of legitimacy, particularly if awareness broadens and there is an increased demand for decision-makers to justify their position. Particularly MEPs who have an openness-agenda could use the call for transparency to push the Commission, the Council as well as their fellow parliamentarians to go public. One could argue that the possibility for national parliamentarians to use public outcry against the executive is presumably even bigger because they have a stronger electoral connection to their constituencies.

\section{Conclusion}

This article has shown how variation in the governance of secrecy in EU foreign and security policy and trade is best explained along two trajectories: Compared to the CFSP, the Lisbon Treaty gave the EP more institutional powers over trade and it has therefore been more successful in pushing back secrecy in this area. Regarding the intensity of secrecy - who gets access to what kind of information - perceptions of legitimacy are key to understand variation. In the CFSP, security and defence information is restricted to the special committee, while access in other areas of foreign policy as well as trade is based on the need-to-know principle. EU foreign policy continues to escape the attention of voters, whereas trade policy has experienced waves of criticism from the public, leading to a push for more transparency. Challenges to the legitimacy of secrecy have also led to greater access to information for MEPs, as was the case for TTIP. Thus, although secrecy is engrained in foreign affairs, it is possible to probe its legitimacy, with at least some success.

At the same time, the majority of MEPs seem only rarely to question the governance of secrecy in the field of EU external relations. Although the EP uses its institutional powers to gain access to information on more substantive issues, the rules and practices for secrecy are rarely contested. The majority of MEPs appear to accept it as appropriate that security officials set the standards across EU external relations, to the 
extent that one could argue that the EP has been co-opted by the secrecy culture of EU security officials. In addition, there are several examples of MEPs privileging parliamentary over public access to information - with reference to the need for secrecy. This gives a different perspective on the problem of asymmetrical information that is held out as a main disadvantage for parliaments in foreign affairs (cf. Kibbe 2010, Raunio and Wagner 2017). Instead of viewing the parliament and executive as antagonists, this article emphasises how they have similar perceptions of the legitimate governance of secrecy. This poses a different set of democratic problems because it deprives the public of the opportunity to judge the actions of the executive and their elected representatives (cf. Rosén and Stie 2017).

There is a lot of variation both in the scope and intensity of secrecy in foreign policy, and not only in the EU. So far, few attempts have been made to explain such differences. Focusing on the instrumental role of parliaments, the aim of this article is to suggest a way of accounting for why secrecy is governed differently across substantive issues, and why more or fewer actors might have access to more or less information. The above analysis shows that when secrecy is accepted as legitimate, it effectively curtails efforts for more openness. Not only because secrecy in itself is seen as appropriate, but also because there is an acceptance that certain actors are the appropriate authorities to determine rules and routines for handling secret information. Thus, while parliamentary institutional power is one factor that can contribute in reducing secrecy, perceptions of legitimacy are key to understand why secrecy prevails in external relations. Lagassé and Saidemann (2017) have argued that party political strategies and the relations between government and opposition contribute to explain why parliamentarians sometimes accept secrecy in foreign policy and at other times not. A main argument of this article is that legitimacy perceptions are crucial to understand why some parliamentarians might refrain from challenging the secrecy regime of the executives. It can account both for why some actors are allowed to set the premise for how secrecy is governed, and why others accept it. In addition, it suggests why certain situations are conducive to effective challenges to the culture of secrecy - such as in the case of TTIP where the legitimacy of secrecy became a publicly contested issue. The next step would be to test the argument on a broader set of cases, as well as to assess the conditions under which 
differences in institutional powers and legitimacy perceptions lead to more or less secrecy in foreign affairs.

\section{References}

Abazi, Vigjilenza, and Maarten Hillebrandt (2015). 'The legal limits to confidential negotiations: Recent case law developments in Council transparency: Access Info Europe and In 't Veld' Common Market Law Review, 52:3, 826-846.

Bieber, Roland (2002). 'Democratic Control of International Relations of the European Union', in Cannizzaro, Enzo (ed.), The European Union as an Actor in International Relations, The Hague: Kluwer Law International, 105-116.

Bjurulf, Bo, and Olle Elgström (2004). 'Negotiating Transparency: The Role of Institutions', Journal of Common Market Studies, 2, 249-269.

Born, Hans, and Marina Caparini (eds.) (2007). Democratic Control of Intelligence Services, London: Routledge.

Bornemann, Lukas, Sarah Denzel, and Enrico Nadbath (2016) 'The 2014 Interinstitutional Agreement: Why did the Council Open its Fortress of Classified Information?', PACO Working Papers, WP01. https://ghum.kuleuven.be/ggs/projects/paco/research\#workingpapers

Bourbeau, Philippe (2014). 'Moving Forward Together: Logics of Securitisation Process', Milllennium: Journal of International Studies, 43:1, 187-206.

Colaresi, Michael (2014). Democracy Declassified. The Secrecy Dilemma in National Security Oxford: Oxford University Press.

Corbett, Richard (2012). 'The evolving roles of the European Parliament and of national parliaments', in Biondi, A., P. Eeckhout and S. Ripley (eds), EU Law after Lisbon, Oxford: Oxford University Press.

Corbett, Richard, Francis Jacobs and Michael Shackelton (2007). The European Parliament, 7th, London: John Harper Publishing.

Coremans, Evelyn (2017) 'From Access to Documents to Consumption of Information: The European Commission Transparency Policy for the TTIP Negotiations', Politics and Governance, 5:3, 29-39.

Curtin, Deidre (2014). 'Overseeing Secrets in the EU: A Demcratic Perspective' Journal of Common Market Studies, 52(3): 684-700.

Elsea, Jennifer (2017). 'The Protection of Classified Information: The Legal Framework', Congressional Research Service, May 18, 2017.

Eriksen, Erik Oddvar (1999). 'Towards a Logic of Justification. On the Possibility of Post-National Solidarity', in Egeberg, Morten, and Per Lægreid (eds.), Organizing political institutions. Essays for Johan P. Olsen, Oslo: Scandinavian University Press.

EUObserver (2010). Secret documents was like 'bad Le Carre novel', MEP says, $18 / 11 / 2010$.

Farrell, Henry, and Adrienne Héritier (2003) 'Institutions Under Codecision: Continuous Constitution-Building in Europe', Governance, 16:4, 577-600.

Farrell, Henry, and Adrienne Héritier (2007) 'Introduction: Contested Competences in the European Union', West European Politics, 30:2, 227-243.

Frank, Thomas M., and Edward Weisband (1974) (eds.). Secrecy and Foreign Policy, Oxford: Oxford University Press.

Goetz, Klaus, and Berthold Rittberger (2017). 'Secrecy and European Politics', West European Politics, XX:X: PAGES 
Heliskoski, Joni, and Leino, Päivi (2006). 'Darkness at the break of noon: The case law on Regulation No. 1049/2001 on access to documents', Common Market Law Review, 43:3, 735-781.

Hill, Christopher (2003). The Changing Politics of Foreign Policy, Basingstoke: Palgrave Macmillan.

Hillebrandt, Maarten (2017). Living transparency: The development of access to documents in the Council of the EU and its democratic implications, $\mathrm{PhD}-$ thesis, University of Amsterdam.

Hillebrandt, Maarten, Deidre Curtin, and Albert Meijer (2014). 'Transparency in the EU Council of Ministers: An Institutional Analysis’, European Law Journal, 20(1), 1-20.

Hix, Simon (2002). 'Constitutional Agenda-Setting Through Discretion in Rule Interpretation: Why the European Parliament Won at Amsterdam', British Journal of Political Science, 32, 259-280.

Hix, Simon and Høyland, Bjørn (2014). 'Political behaviour in the European Parliament', in Martin, Shane, Thomas Saalfeld and Kaare Strøm (eds.) The Oxford Handbook of Legislative Studies Oxford: Oxford University Press, 591-608.

Hood, Christopher, and David Heald (2006). Transparency: The Key to Better Governance? Oxford: Oxford University Press.

House of Lords (2001) 'Access to documents: The Council Decision of 14 August 2000', Select Committee on Eurpean Union, Eight Report, 06/02/2001.

Huysmans, J. 2014. Security Unbound. Enacting Democratic Limits. London: Routledge.

Jancic, Davor (2017). 'TTIP and legislative-executive relations in EU trade policy', West European Politics, 40:1, 202-221.

Jupille, Joseph, James A. Caparoso, and Jeffrey T. Checkel (2013). 'Integrating Institutions: Rationalism, Constructivism, and the Study of the European Union', Comparative Political Studies, 36:7, 7-40.

Kibbe, Jennifer (2010). 'Congressional Oversight of Intelligence: Is the Solution Part of the Problem?', Intelligence and National Security, 25:1, 24-49

Kucik, Jeffrey, and Krzysztof J. Pelc (2015). 'Measuring the Cost of Privacy: A Look at the Distributional Effects of Private Bargaining', British Journal of Political Science, 46:4, 861-889.

de fine Licht, Jenny, Daniel Naurin, Peter Esaiasson, and Mikael Gilljam (2014). 'When Does Transparency Generate Legitimacy? Experimenting on a Context-Bound Relationship, Governance, 27:1, 111-134.

Maurer, A. (2015) 'Comparative Study on Access to Documents (and confidentiality rules) in international negotiations', Study for the European Parliament, PE 549.033.

Olsen, Johan P. (2009) 'Change and continuity: an institutional approach to institutions of democratic government', European Political Science Review, $1: 1,3-32$.

Olsen, Johan P. (2010) Governing through Institution Building. Institutional Theory and Recent Experiments in Democratic Organization Oxford: Oxford University Press.

Ostermann, Falk (2017). 'France's reluctant parliamentarisation of military deployments: the 2008 constitutional reform in practice', West European Politics, 40:1, 101-118. 
Peters, Dirk and Wolfgang Wagner (2014). 'Executive privilege or parliamentary proviso? Exploring the sources of parliamentary war powers', Armed Forces and Society, 40:2, 310-331.

Pozen, David (2010). 'Deep Secrecy', Stanford Law Review, 62:2, 257-339.

Raube, Kolja (2012). 'The European External Action Service and the European Parliament ', The Hague Journal of Diplomacy, 7:1, 65-80.

Raunio, T. (2014). 'Legislature and Foreign Policy', in in Martin, Shane, Thomas Saalfeld and Kaare Strøm (eds.) The Oxford Handbook of Legislative Studies, Oxford: Oxford University Press, 543-566.

Raunio, Tapio, and Wagner, Wolfgang (2017). 'Towards Parliamentarization of Foreign and Security Policy?', West European Politics, 40:1, 1-19.

Reichard, Martin (2006). The EU-NATO Relationship: A Legal and Political Perspective (Aldershot: Ashgate).

Rittberger, Berthold (2012). 'Institutionalizing Representative Democracy in the European Union: The Case of the European Parliament', Journal of Common Market Studies, 50:S1, 18-37.

Roberts, Alasdair (2006). Blacked Out. Government Secrecy in the Information Age, Cambridge: Cambridge University Press.

Rosén, Guri (2015). 'EU Confidential: The European Parliament's Involvement in EU Security and Defence Policy', Journal of Common Market Studies, 53:2, 383398.

Rosén, Guri (2017). 'The impact of norms on political decision-making: How to account for the European Parliament's Empowerment in EU External Trade Policy', Journal of European Public Policy, 24:10, 1450-1470.

Rosén, Guri and Anne Elizabeth Stie (2017. 'Not Worth the Net Worth? The Democratic Dilemmas of Privileged Access to Information', Politics and Governance, 5:3, 51-61.

Scheppele, Kim (1988). Legal Secrets: Equality and Efficiency in the Common Law, Chicago: University of Chicago Press.

Sjursen, H. (2006) 'The EU's Common Foreign and Security Policy: the quest for democracy', Journal of European Public Policy, 11:8, 1069-1077.

Stasavage, David (2004). 'Open-Door or Closed-Door? Transparency in Domestic and International Bargaining', International Organization, 58:4, 667-703.

Tallberg, Jonas (2006). Leadership and Negotiation in the European Union (Cambridge: Cambridge University Press).

Tappert, Malin (2003). 'European Parliament resigned to limited oversight of ESDP?', European Security Review, no. 16.

Thompson, Dennis F. (1999). 'Democratic Secrecy' Political Science Quarterly, 114:2, 181-193.

Vanhoonacker, Sophie (2011). 'The Institutional Framework', in Hill, Christopher, and Michael Smith (eds.), International Relations and the European Union, 2nd, Oxford: Oxford University Press, 75-100.

Wills, Aidan, and Vermeulen, Mathias (2011). 'Parliamentary Oversight of Security and Intelligence Agencies in the European Union', Study for the European Parliament, PE 453.207. 